\title{
Adverse Influence of Radio Frequency Background on Trembling Aspen Seedlings: Preliminary Observations
}

\author{
Katie Haggerty \\ P.O. Box 553, Lyons, CO 80540, USA \\ Correspondence should be addressed to Katie Haggerty, katiemh108@yahoo.com \\ Received 21 June 2009; Revised 31 October 2009; Accepted 17 February 2010 \\ Academic Editor: Terry L. Sharik \\ Copyright () 2010 Katie Haggerty. This is an open access article distributed under the Creative Commons Attribution License, \\ which permits unrestricted use, distribution, and reproduction in any medium, provided the original work is properly cited.
}

Numerous incidents of aspen decline have been recorded in North America over the past half century, and incidents of very rapid mortality of aspen clones have been observed in Colorado since 2004. The radio frequency (RF) environment of the earth has undergone major changes in the past two centuries due to the development and use of electricity in power and communications applications, and the anthropogenic RF background continues to increase in intensity and complexity. This study suggests that the RF background may have strong adverse effects on growth rate and fall anthocyanin production in aspen, and may be an underlying factor in aspen decline.

\section{Introduction}

Incidents of aspen decline in North America have been observed since the mid-20th Century [1-3]. Stands at the limits of aspen's lower elevation range, on sites with poor drainage, with limited water [4] or nutrient supply [5], are more susceptible to decline. Stand age and clonal differences are also factors in susceptibility to decline [6]. Factors initiating decline include: defoliation by insects, damage caused by wildlife, severe drought, and extreme weather incidents [7]. Damage caused by these factors can diminish the vigor of affected clones and make them vulnerable to opportunistic fungal pathogens and insects [8]. The concept of forest decline has been used to describe the interaction of these various factors; however, the underlying causes of aspen decline are not well understood [9]. Since 2004, incidents of very rapid aspen clone mortality have been seen in Colorado [10]. Because the electromagnetic (EM) environment of the earth has changed radically in the past two centuries, this study investigates the possibility that anthropogenic changes in this environment, particularly in the radio frequency (RF) spectrum, are adversely affecting growth and health of aspen populations, making them vulnerable to decline.
Electromagnetic energy from the sun is essential for life on earth. Plants rely on inputs of EM energy for photosynthesis and for regulation of periodic functions (flowering, shoot and root growth, respiration, and dormancy). A plant's response to EM energy is dependant on frequency, timing, and intensity of the signal. The source of the EM input, however, makes no difference. Timing of plant processes is an important mechanism for plant protection and efficient functioning in changing day/night and seasonal environmental conditions [11]. Although photosynthesis requires fairly strong energy input in the blue and red visual frequencies (full sun/shade) [12], photoperiodic responses in plants are typically triggered by energy inputs in the red and far-red frequencies that are in the range of $10^{-4}$ times the energy required for photosynthesis, and even a brief flash of light during a plant's subjective night can be enough to trigger a short night response, strongly affecting plant behavior and morphology [13]. The radio frequencies, lower than 300 gigahertz, are below visual and infrared frequencies in the electromagnetic spectrum. The earth's natural RF environment has a complex periodicity that has been more or less the same within the lifespan of modern tree taxa. Before 1800, the major components of this environment were broadband radio noise from space (galactic noise), from 
lightning (atmospheric noise), and a smaller RF component from the sun [14]. Because of the periodic nature of the naturally occurring RF background, plants may have evolved to use those environmental signals, as well as visible light, to regulate periodic functions, and therefore they may be sensitive to anthropogenic RF input. The intensity of the human-generated RF environment has increased gradually since about 1800. This background of RF pollution is now many times stronger than the naturally occurring RF environment. From the perspective of evolutionary time, the change can be considered sudden and dramatic $[14,15]$.

Many experiments have been conducted investigating possible effects of RF exposure on plants and animals. Generally, exposures to particular single frequencies at particular, usually fairly high intensities, have been used in these previous experiments [16]. However, the assumption seems to have been made that the low-level background of RF pollution has no effect on biological systems. Therefore, not only has this particular phenomenon not been studied, but it has been generally disregarded in earlier experiments designed to look for effects of RF exposure. Results of those previous experiments are often difficult to duplicate, and it may be that the anthropogenic RF background has been a confounding factor. However, for some RF effects on biological systems, consistent results have been documented in previous experiments: growth rates of plants [17] and fungi [18] can be increased or decreased by RF exposure. Exposure to RF signals can induce plants to produce more meristems [19], affect root cell structure [20, 21], and induce stress response in plant species, causing biochemical changes [22]. Effects on circadian rhythms in several animal species have been documented [23]. Some possible mechanisms of effect have been identified [24]. This experiment investigates the effects of the radio frequency background on aspen seedlings. The objective of this preliminary study was to determine if aspens respond to the current RF background in ways that result in reduced growth, or in increased susceptibility to pathogens.

1.1. Study Area. The experiment was conducted in a rural area near Lyons, Colorado: at $40.29^{\circ}$ Latitude and $-105.28^{\circ}$ Longitude, at an altitude of 1,700 meters, and on a northfacing slope. The ecological system in the area of the experiment is Rocky Mountain Lower Montane. The site was about 400 meters below the lower elevation of aspen's natural range in Colorado. The north-facing slope was chosen as a somewhat cooler microclimate than other aspects. Vegetation included various grasses, which were mowed on the $8 \times 10 \mathrm{~m}$ experimental plot. Vegetation in the east, south, and west directions from the experiment included: wild grasses and various low shrubs, rabbit brush (Chrysothamnus nauseosus), sage (Artemisia tridentata), wild currant (Ribes cereum), chokecherry (Prunus virginiana), yucca (Yucca angustifolia), and skunkbush (Rhus trilobata). North of the experiment, there were large cottonwood trees along the river, with grass and chokecherry undergrowth.

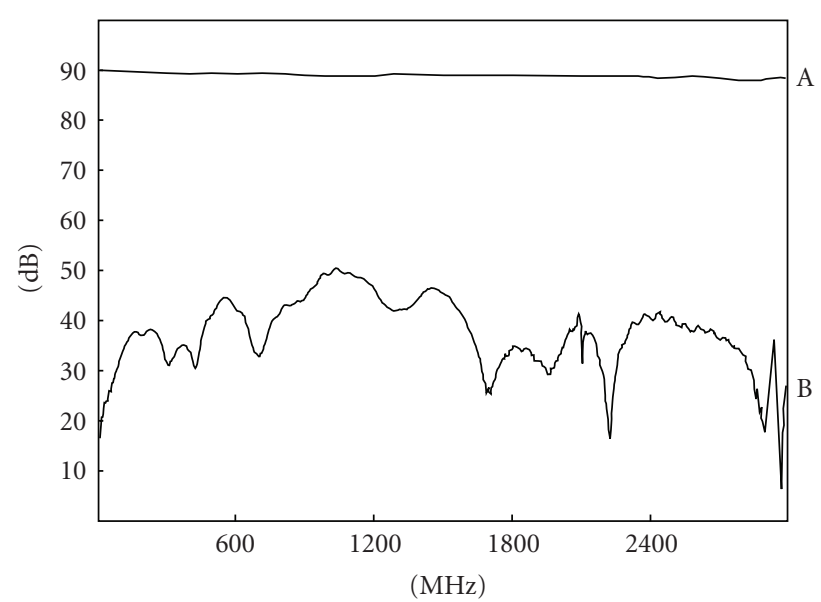

Figure 1: The aluminum screen material in the configuration used for this experiment was tested at NIST in Boulder, CO. From $1.0 \mathrm{MHz}$ to $3.0 \mathrm{GHz}$, its effectiveness in blocking RF signals was found to vary from $40 \mathrm{~dB}$ to $73 \mathrm{~dB}$ across the entire range of frequencies. $\mathbf{X}$ axis = Radio frequency from $1.000 \mathrm{MHz}$ to $3000.000 \mathrm{MHZ}$ in increments of $300.000 \mathrm{MHz}$ left to right. $\mathbf{Y}$ axis $=$ Decibel scale. Reference signal level was 90 dB. A = Reference signal. $\mathrm{B}=$ Attenuated signal.

1.2. Materials and Methods. In order to create an environment free of RF signals, a Faraday cage was built, using two layers of aluminum window screen supported by a bamboo frame. Cage dimensions were $75 \mathrm{~cm}$ by $75 \mathrm{~cm}$ by $120 \mathrm{~cm}$. The aluminum screen material in the configuration used for this experiment was tested at a laboratory of the National Institute of Standards and Technology (NIST) in Boulder, CO. From $1.0 \mathrm{MHz}$ to $3.0 \mathrm{GHz}$, its effectiveness in attenuating RF signals was found to vary from $40 \mathrm{~dB}$ to $73 \mathrm{~dB}$ across the entire range of frequencies (Figure 1). Theoretically, an enclosure made of this material would reduce signal intensity by a factor of $10^{-4}$ to $10^{-7.3}$, blocking essentially all ambient RF energy, including the naturally occurring RF background. In practice, the shielding effectiveness of a Faraday cage made of this material could be somewhat less than that of the material itself due to gaps or imperfect electrical contact at seams and closures, and to the internal RF acoustical properties of the cage. A similar cage was constructed as a control, with fiberglass screen, which is not conductive and which does not block RF signals, instead of aluminum. A transistor radio was used to test the effectiveness of the cages to block the RF background. No radio stations could be picked up inside the Faraday cage. In both the mock-Faraday cage and the uncaged area, numerous stations were received in the AM and FM bands. A sweep of RF background at the site, June 6, 2009, using an Anritsu spectrum analyzer, showed that field intensity ranged from $-117 \mathrm{dBm}$ to $-87 \mathrm{dBm}$ at frequencies from 1 to $1,000 \mathrm{MHz}$. Mean field intensity was $-109 \mathrm{dBm}$.

On May 28, 2007, 30 aspen seedling plugs were obtained from the Colorado State Forest Service (CSFS) nursery in Fort Collins, Colorado. Seed for these seedlings came from Caffey County near Salida Colorado, approximately 


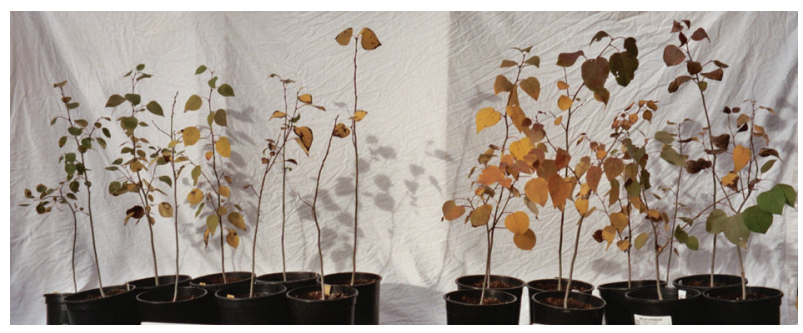

Figure 2: October 6, 2007. Mock-shielded seedlings on the left and shielded seedlings on the right, the latter showing more total leaf area, stronger fall leaf coloration, and minimal leaf necrosis symptoms.

$195 \mathrm{~km} \mathrm{SSW}$ of the experiment site, at an elevation of about 2,100 meters. The seeds were germinated in June 2006 at the CSFS Nursery, and the resulting seedlings were grown in a shade house in a Styrofoam planter-block of 30 seedling plugs. The seedlings had leafed out in early spring and, when purchased on May 28, 2007, were not producing new leaves. Seedlings were transplanted into no. 1 black gallon plastic pots on June 5, 2007 using a commercial potting medium, Black Gold, composed of: $45-55 \%$ Canadian sphagnum peat moss, compost, pumice, perlite, and composted worm castings (N .05\%: water soluble .006\%, water insoluble .044\%). Since only 27 seedlings were needed for the experiment, due to space restrictions, the three smallest seedlings were discarded. The remaining seedlings were relatively uniform in height, stem diameter, and leaf development, and the leaves appeared healthy and green. The 27 seedlings were assigned to 3 groups of 9 seedlings each, with variation in size distribution distributed equally among the 3 groups. After potting, the three groups were photographed and randomly assigned to the mock-shielded cage, the shielded cage, or to the unshielded area. The experiment began June 6, 2007. All treatments in the experiment were exposed to full sun from sunrise to late afternoon. There was a distance of three meters between treatment enclosures. All seedlings in the experiment were watered at the same time $1-2 \times$ per week, depending on the weather, using Lyons water. Seedlings were watered with a weak solution of fertilizer (5-10-5) on July 29, 2007, and otherwise were not fertilized.

Two sets of a calibrated thermometer and humidity gauge were used to compare temperature and humidity readings between cages under various weather conditions and times of day and night. The monitoring devices were placed in the middle of the monitored treatment enclosure, just above the top of the pots. A board was placed south of the devices to provide shade. A lux meter was used to measure light intensity in the treatment areas. Shielding reduced light intensity by $35 \%$ for the mock-shielded enclosure and $40 \%$ for the RFshielded enclosure. Naturally occurring sunlight intensity was not reduced for the group that was not shielded. Except for the difference in RF background intensity, conditions in the shielded and mock-shielded enclosures were very similar. The unshielded seedlings were exposed to higher light levels (full sun), higher airflow, and generally lower humidity than

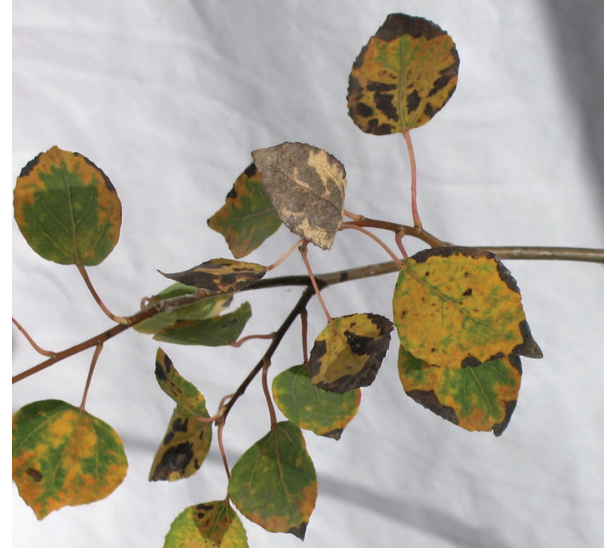

Figure 3: Unshielded seedling, showing green to yellow leaf coloration and gray to brown necrotic leaf tissue, Oct. 6, 2007.

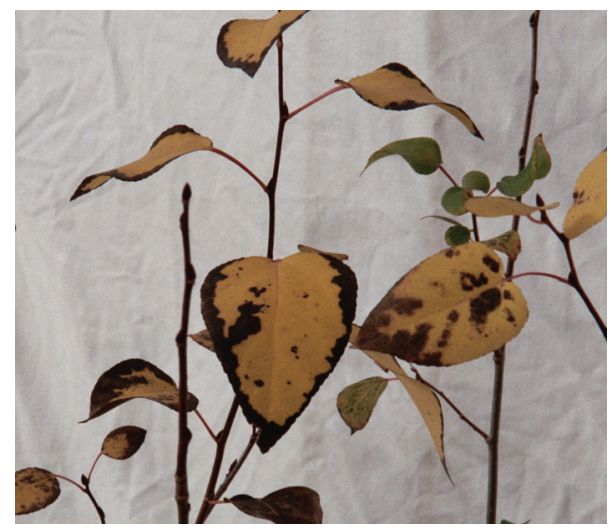

FIGURE 4: Mock-shielded seedling, exhibiting yellow leaf coloration and brown lesions, Oct. 6, 2007.

the shielded and mock-shielded treatments since they were not in a screened enclosure.

1.3. Measurements. After seedlings were transplanted and placed in the three treatment enclosures in early June, they began to grow again. Because of that, there was a shoot node dividing spring growth from the summer growth phase that was easy to identify. Measurement of active leader (shoot) length was taken from the tip of the shoot down to that first shoot node, so leader length measured was only that produced after the experiment began on June 6, 2007. For leaves emerging directly from a main stem, leader length was recorded as $0.00 \mathrm{~cm}$.

On July 28-29, 2007, measurements of active leader length and width of each leaf on each active leader were made on all seedlings in the experiment. Leaves had not begun to drop at that time, and the great majority of them in all treatment groups appeared healthy and green. Leaf width was converted into estimated leaf area using an algorithm (Leaf Area $\left(\mathrm{cm}^{2}\right)=0.637 *$ Leaf Diameter $\left.(\mathrm{cm})^{1.951}\right)$ developed by W.D. Shepperd of the USDA forest Service's Rocky Mountain Research Station [25]. After measurements were taken, all seedlings were returned to their cages. October 5-6 photos 


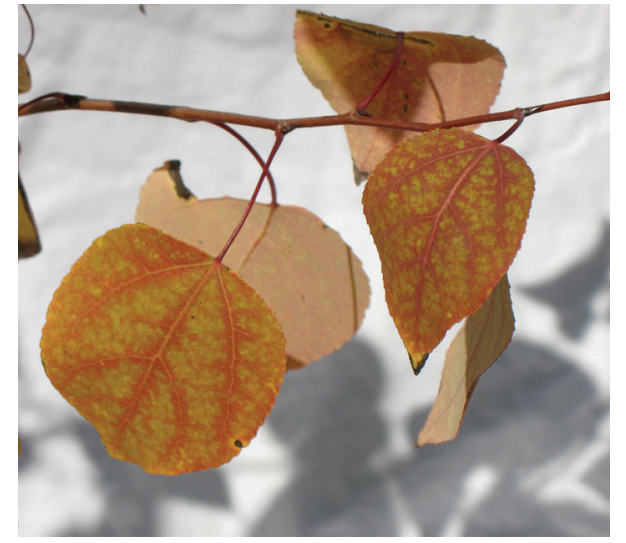

FIGURE 5: Shielded seedling, showing red petioles and veins on light green leaf tissue, and very little leaf tissue affected by necrosis. Oct. 6, 2007.

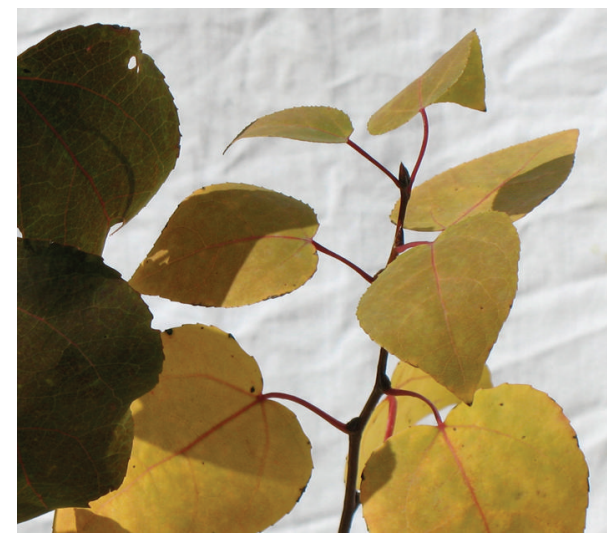

Figure 6: Shielded seedling. Combination of red veins and green leaf tissue makes leaves look black (left side of photo), Oct. 6, 2007.

were taken showing differences in leaf coloration, and relative leaf area affected by necrotic lesions.

\section{Results}

Seven seedlings in each RF-exposed group and eight seedlings in the shielded group produced active leaders and new leaves during the experiment. The RF shielded group evidenced more vigorous growth, producing $74 \%$ more total leader length and $60 \%$ more leaf area than the mock-shielded group, though the number of leaves produced by both groups was nearly the same (Table 1 ). The two RF-exposed groups' morphology and behavior were very similar and within the current norm for aspen, including absence of fall anthocyanin production, and extensive leaf area affected by necrotic lesions in fall senescing leaves. On active leaders, the shielded group showed fall production of anthocyanins far outside the norm, absence of fall leaf tissue necrotic lesions, and a wide range of fall colors: bright orange, yellow, green, dark red, and black (a combination of dark green

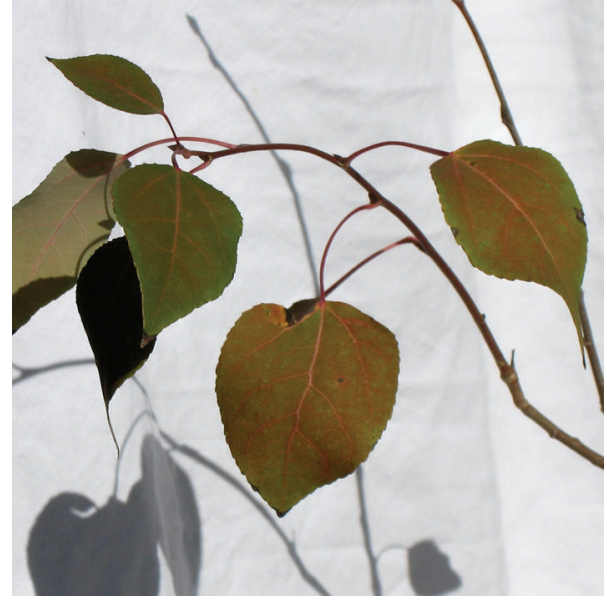

FIGURE 7: Shielded seedling, with leaves on active leaders mainly free of necrotic lesions, and leaf veins and petioles red, Oct. 6, 2007.

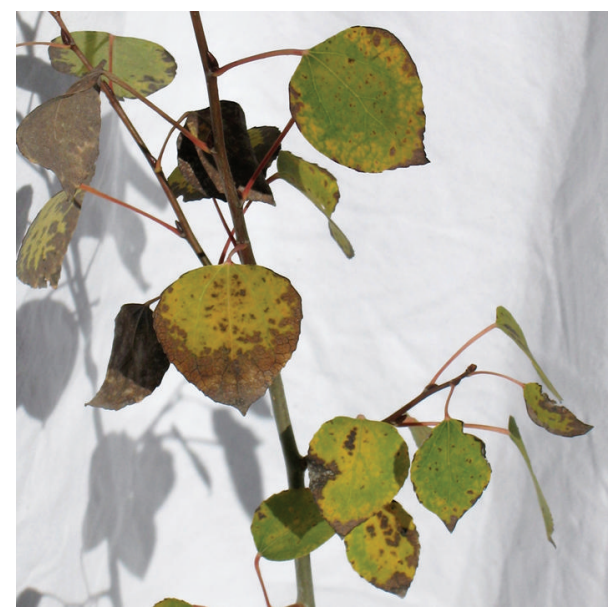

FIGURE 8: Mock-shielded seedling, showing all leaves affected by necrotic lesions to some extent, leaf veins yellow or green, and petioles light red to pink, Oct. 6, 2007.

leaf tissue with red veins). Shielded leaves produced in the spring flush (before treatment), however, were similar in appearance to leaves in the two exposed groups in color, size, and incidence of lesions. All of the shielded leaves on active leaders had dark to bright red veins and petioles indicating strong anthocyanin production (Figure 2). On October 5, 2007, unshielded and mock-shielded seedlings had leaf tissue ranging in color from yellow to green, and a high percentage of leaf tissue in both exposed groups displayed necrotic lesions (Figures 3 and 4). Shielded seedlings had larger leaves, petioles and leaf veins were red, and tissue colors varied from yellow to dark green (Figure 5). Some shielded leaves looked black because of the combination of red veins and dark green tissue (Figure 6). Leaves on active leaders in the shielded group were substantially free of leaf tissue lesions (Figure 7), but unshielded and mock-shielded leaves were all affected to some extent by leaf tissue necrosis (Figure 8). 
TABLE 1: Various characteristics of aspen seedlings following one of three RF treatments.

\begin{tabular}{|c|c|c|c|}
\hline & \multicolumn{3}{|c|}{ Treatment } \\
\hline $\begin{array}{l}\text { Seedling } \\
\text { Characteristic }\end{array}$ & Not-Shielded & Mock-Shielded & Shielded \\
\hline No. leaders & $4(0,6)^{*}$ & $2(0,7)$ & $3(0,3)$ \\
\hline Leader length $(\mathrm{cm})$ & $22(0,52)$ & $17(0,43)$ & $31(0,53)$ \\
\hline No. Leaves & $27(0,37)$ & $16(0,34)$ & $16(0,31)$ \\
\hline Leaf area $\left(\mathrm{cm}^{2}\right)$ & $87.4(0,165.8)$ & $72.8(0,186.7)$ & $170(0,219.8)$ \\
\hline $\begin{array}{l}\text { No. seedlings } \\
\text { producing leaders } \\
\text { and leaves }\end{array}$ & 7 & 7 & 8 \\
\hline $\begin{array}{l}\text { No. seedlings out } \\
\text { of } 9 \text { producing } \\
\text { anthocyanins }\end{array}$ & 0 & 0 & 8 \\
\hline
\end{tabular}

${ }^{*}$ Median $(\min , \max ) \mathbf{n}=\mathbf{9}$.

\section{Discussion}

Because only one treatment enclosure was established for each treatment, differences among groups could not be analyzed statistically. Results of this experiment do, however, suggest several possible effects of RF exposure on aspen. Those effects include reduction of shoot length and leaf area, suppression of fall anthocyanin production, and increased incidence of necrotic leaf tissue in fall senescing leaves. Reduced vigor in the two RF-exposed groups is demonstrated by lower total leader length and diminished production of leaf area relative to the shielded group. A study [26] comparing mutant nonanthocyanin-producing strains of fall anthocyanin-producing species, Cornus sericea, Vaccinium elliottii, and Viburnum sargentii, showed very similar results to this experiment with regard to fall color in that extensive necrotic leaf tissue was seen in nonanthocyanin-producing mutants during fall leaf senescence and leaves dropped while still green. Wild-type strains of those species, which produced anthocyanins, did not exhibit necrotic lesions. In that study, leaf tissue damage in mutant strains was shown to be caused by photooxidative stress. During fall leaf senescence photosynthetic mechanisms become vulnerable to damage by visible light. Anthocyanins shield the photosynthetic apparatus from high light levels, preventing photoinhibition and damage to leaf tissue due to light stress. Transport of foliar nutrients requires energy provided by photosynthesis [27], and since the majority of nutrients in overwintering deciduous trees are derived from foliar nutrient transport during autumn leaf senescence, differences in anthocyanin production could have major effects on plant fitness [28].

Since all leaves on active leaders in the shielded aspen group showed striking fall coloration, and since each of the seedlings was genetically distinct, it appears that the Faraday cage environment favored strong production of anthocyanins during fall leaf senescence. Five bright sunny days, Sept. $30-$ Oct. 4 , accompanied by cool nights $\left(\sim 5^{\circ} \mathrm{C}\right)$ preceding the appearance of red leaf coloration, provided optimal conditions for anthocyanin production. Although shielding materials substantially reduced light levels in

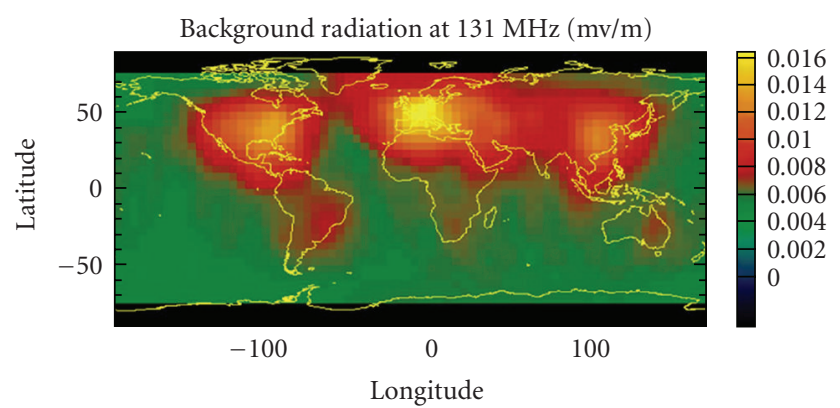

Figure 9: Forte Satellite: $131 \mathrm{MHz}$ RF background 2000. Areas of highest radio background intensity occur in the eastern United States, central Europe, and China. Acquired by the Los Alamos National Laboratory FORTE spacecraft. Principal investigator A.R. Jacobson.

the two caged groups (mock-shielded and shielded), the behavior and appearance of the two RF-exposed groups (mock-shielded and unshielded) were most similar, both showing no apparent anthocyanin production, leaf tissue remaining light green or yellow, and a high percentage of leaf tissue affected by necrotic lesions.

3.1. Radio Frequency Environment. Beginning around 1800, EM experimentation, establishment of electrical telegraph systems, generation and distribution of electricity, and the use of broadcast signals gradually began to fill the region of the electromagnetic spectrum below $300 \mathrm{GHz}$. Currently, the RF spectrum is quite crowded, and new technologies are constantly being developed to allow more information to be transmitted on the available frequencies [29]. Unintended broadband RF noise is created as a byproduct of electrical power generation, transmission, and use. These human-made RF sources create a background noise (as differentiated from signal) level generally 10 to 100 times stronger than the naturally occurring background of galactic noise and atmospheric noise at frequencies below $30 \mathrm{MHz}$ [14]. Human-generated signal intensities in large regions of the $\mathrm{RF}$ spectrum are in the range of $10^{3}-10^{6}$ times stronger than the naturally occurring RF background in urban areas [15]. Because terrestrial and satellite RF sources are numerous and widely dispersed globally, and since below $30 \mathrm{MHz}$ radio signals can travel great distances around the earth by bouncing between the ionosphere and the earth's surface [14], currently a strong human-generated RF background exists at every point on the earth's surface, although radio field strength is relatively greater in the most populous and urbanized areas. Globally, the highest field strengths occur in central Europe, the eastern United States, and in China (Figure 9). Forest decline was first recognized and defined based on observed events in central Europe and the eastern US, and China, at this time, is experiencing rapid desertification.

3.2. Forest Decline. The first widely recognized incidents of forest decline [30] began in the late 1970s. In a European study [31], stress factors related to forest defoliation were 
found to be age, altitude, drought, and various types of air pollution, in descending order of importance. Although the statistical correlation was high for some of these effects, because the number of samples was large, the effects documented were quite small and altogether could account for only $15-55 \%$ of the observed decline, depending on species. No temperature variables were found to have significant effects. In several studies, climate change was found not to be a causal agent in forest decline $[32,33]$. There is evidence, however, that trees involved in forest decline are less tolerant of extreme weather conditions. Freeze damage, possibly indicating disrupted dormancy, for instance, has been noted as one symptom of forest decline where temperature and/or precipitation pattern changes were not evident [32, 34]. More recently, it has been shown that mortality rates of all dominant tree species in the western United States have been doubling every 17-29 years in old growth forests, and that recruitment of new trees is now occurring at a lower rate than mortality [35]. Since aspen decline and other tree decline incidents worldwide have similar symptoms, and since no definitive explanation has been found for those events, it seems plausible that their decline may be related to RF exposure.

Changes in health and growth rates of aspen and other plants, due to increasing RF exposure, would have been difficult to detect for two reasons: first, because the $\mathrm{RF}$ background is widely dispersed globally, comparisons between plant populations, even over great distances, would always have been between RF-exposed groups, even though exposure levels would vary with relative proximity to RF sources. Second, it is difficult to compare the health and appearance of plants living today to those living 200 years ago, though some comparisons can be made from previous research data, tree ring data, and pollen samples, for instance. Changes would have occurred very slowly over time, from the human perspective, and would have been widely dispersed geographically so that, at any particular time, RF-altered plant morphology and behavior would have been normal, the norm, by definition. Plants and animals have in previous experiments been shown to respond in various ways to RF exposure. Growth of organisms may be inhibited or accelerated by RF exposure, thus possibly affecting interactions at the level of communities and ecosystems from microscopic to global scales. In the case of aspen, reduced plant vigor and adverse effects on fall storage of nutrients due to RF exposure could leave seedlings vulnerable to pathogens and less able to accommodate other environmental stress.

\section{Conclusions}

The results of this preliminary experiment indicate that the RF background may be adversely affecting leaf and shoot growth and inhibiting fall production of anthocyanins associated with leaf senescence in trembling aspen seedlings. These effects suggest that exposure to the RF background may be an underlying factor in the recent rapid decline of aspen populations. Further studies are underway to test this hypothesis in a more rigorous way.

\section{Acknowledgments}

The author wishes to thank an anonymous reviewer for many helpful comments, Dr Wayne Shepperd for advice and encouragement, the Marbrook Foundation, Sangha Foundation, Brian Haggerty, Alan Haggerty, Hoshi Motors, and Barbara and Bruce Leaf for financial support, Brigitte Lause for editorial advice, and Patricia Kluck and Roland Rodriguez for technical support.

\section{References}

[1] T. J. Basham, "Decay of trembling aspen," Canadian Journal of Botany, vol. 36, pp. 491-505, 1958.

[2] J. H. Stoeckler, "Soil factors affecting the growth of trembling aspen forests in the lake states," University of Minnesota Agricultural Experiment Station Technical Bulletin, vol. 233, 1960.

[3] D. L. Bartos, "Landscape dynamics of aspen and conifer forests," in Proceedings of the Sustaining Aspen in Western Landscapes Symposium, USDA Forest Service Proceedings RMRS-P-18, pp. 5-14, June 2000.

[4] T. T. Kozlowski, "Responses of woody plants to flooding and salinity," Tree Physiology Monograph no. 1, Heron Publishing, Victoria, British Colombia, Canada, 1997.

[5] X. Yao, S. J. Titus, and S. E. MacDonald, "A generalized logistic model of individual tree mortality for aspen, white spruce, and lodgepole pine in Alberta mixedwood forests," Canadian Journal of Forest Research, vol. 31, no. 2, pp. 283-291, 2001.

[6] W. J. Shields Jr. and J. G. Bockheim, "Deterioration of aspen clones in the Great lakes Region," Canadian Journal of Forest Research, vol. 11, pp. 530-537, 1981.

[7] B. R. Frey, V. J. Lieffers, E. H. Hogg, and S. M. Landhausser, "Predicting landscape patterns of aspen dieback: mechanisms and knowledge gaps," Canadian Journal of Forest Research, vol. 34, no. 7, pp. 1379-1390, 2004.

[8] R. M. Cox and J. W. Malcolm, "Effects of duration of a simulated winter thaw on dieback and xylem conductivity of Betula papyrifera," Tree Physiology, vol. 17, no. 6, pp. 389-396, 1997.

[9] E. H. Hogg, "Simulation of interannual responses of trembling aspen stands to climatic variation and insect defoliation in western Canada," Ecological Modelling, vol. 114, no. 2-3, pp. 175-193, 1999.

[10] J. J. Worrall, L. Egeland, T. Eager, et al., "Rapid mortality of Populus tremuloides in southwestern Colorado, USA," Forest Ecology and Management, vol. 255, no. 3-4, pp. 686-696, 2008.

[11] D. Vince-Prue, "The duration of light and photoperiodic responses," in Photomorphogenisis in Plants, pp. 447-490, Kulwer Academic Publishers, 2nd edition, 1994.

[12] O. Bjorkman, "Responses to different quantum flux densities," in Encyclopedia of Plant Physiology, New Series, P. S. Lange, P. S. Nobel, C. B. Osmond, and H. Zeiger, Eds., vol. 12A, pp. 57107, Springer, Berlin, Germany, 1991.

[13] A. L. Mancinelli, "The physiology of phytochrome action," in Photomorphogenisis in Plants, pp. 211-269, Kluwer Academic Publishers, 2nd edition, 1994.

[14] N. M. Maslin, HF Communications, a Systems Approach, Plenum Press, New York, NY, USA, 1987.

[15] F. H. Sanders, B. J. Ramsey, and V. S. Lawrence, "Broadband spectrum survey at Los Angeles, California," NTIA Report 97336, 1997. 
[16] H. Berg, "Problems of weak electromagnetic field effects in cell biology," Bioelectrochemistry and Bioenergetics, vol. 48, no. 2, pp. 355-360, 1999.

[17] I. Y. Petrov, T. V. Moiseeva, and E. V. Morozova, "Possibility of correction of vital processes in plant cell with microwave radiation," in Proceedings of the IEEE International Symposium on Electromagnetic Compatibility, pp. 234-235, December 1991.

[18] A. Berg and H. Berg, "Influence of ELF sinusoidal electromagnetic fields on proliferation and metabolite yield of fungi," Electromagnetic Biology and Medicine, vol. 25, no. 1, pp. 71-77, 2006.

[19] M. Tafforeau, M.-C. Verdus, V. Norris, et al., "Plant sensitivity to low intensity $105 \mathrm{GHz}$ electromagnetic radiation," Bioelectromagnetics, vol. 25, no. 6, pp. 403-407, 2004.

[20] M. B. Bitonti, S. Mazzuca, T. Ting, and A. M. Innocenti, "Magnetic field affects meristem activity and cell differentiation in Zea mays roots," Plant Biosystems, vol. 140, no. 1, pp. 87-93, 2006.

[21] W. Wawrecki and B. Zagorska-Marek, "Influence of a weak DC electric field on root meristem architecture," Annals of Botany, vol. 100, no. 4, pp. 791-796, 2007.

[22] D. Roux, A. Vian, S. Girard, et al., "Electromagnetic fields $(900 \mathrm{MHz})$ evoke consistent molecular responses in tomato plants," Physiologia Plantarum, vol. 128, no. 2, pp. 283-288, 2006.

[23] W. Engelmann, W. Hellrung, and A. Johnsson, "Circadian locomotor activity of Musca flies: recording method and effects of $10 \mathrm{~Hz}$ square-wave electric fields," Bioelectromagnetics, vol. 17, no. 2, pp. 100-110, 1996.

[24] T. D. Xie, P. Marszalek, Y.-D. Chen, and T. Y. Tsong, "Recognition and processing of randomly fluctuating electric signals by Na,K-ATPase," Biophysical Journal, vol. 67, no. 3, pp. 1247-1251, 1994.

[25] W. D. Sheppard, "Initial growth, development, and clonal dynamics of regenerated aspen in the Rocky Mountains," Tech. Rep. Research Paper RM-312, USDA Forest Service, 1999.

[26] W. A. Hoch, E. L. Singsaas, and B. H. McCown, "Resorption protection. Anthocyanins facilitate nutrient recovery in autumn by shielding leaves from potentially damaging light levels," Plant Physiology, vol. 133, no. 3, pp. 1296-1305, 2003.

[27] F. S. Chapin III and L. Moilanen, "Nutritional controls over nitrogen and phosphorus resorption from Alaskan birch leaves," Ecology, vol. 72, no. 2, pp. 709-715, 1991.

[28] L. Cheng and L. H. Fuchigami, "Growth of young apple trees in relation to reserve nitrogen and carbohydrates," Tree Physiology, vol. 22, no. 18, pp. 1297-1303, 2002.

[29] R. D. Ekers and J. F. Bell, "Radio frequency interference," ATNF CSIRO, http://arxiv.org/abs/astro-ph/0002515v1.

[30] P. D. Manion, Tree Disease Concepts, Prentice-Hall, Englewood Cliffs, NJ, USA, 2nd edition, 1991.

[31] J. M. Klap, J. H. Oude Voshaar, W. De Vries, and J. W. Erisman, "Effects of environmental stress on forest crown condition in Europe-part IV: statistical analysis of relationships," Water, Air, and Soil Pollution, vol. 119, no. 1-4, pp. 387-420, 2000.

[32] S. B. McLaughlin, D. J. Downing, T. J. Blasing, E. R. Cook, and H. S. Adams, "An analysis of climate and competition as contributors to decline of red spruce in high elevation Appalachian forests of the Eastern United states," Oecologia, vol. 72, no. 4, pp. 487-501, 1987.

[33] F. Biondi and J. E. Fessenden, "Response of lodgepole pine growth to $\mathrm{CO}_{2}$ degassing at Mammoth Mountain, California," Ecology, vol. 80, no. 7, pp. 2420-2426, 1999.
[34] P. G. Schaberg, P. E. Hennon, D. V. D’Amore, and G. J. Hawley, "Influence of simulated snow cover on the cold tolerance and freezing injury of yellow-cedar seedlings," Global Change Biology, vol. 14, no. 6, pp. 1282-1293, 2008.

[35] P. J. van Mantgem, N. L. Stephenson, J. C. Byrne, et al., "Widespread increase of tree mortality rates in the Western United States," Science, vol. 323, no. 5913, pp. 521-524, 2009. 

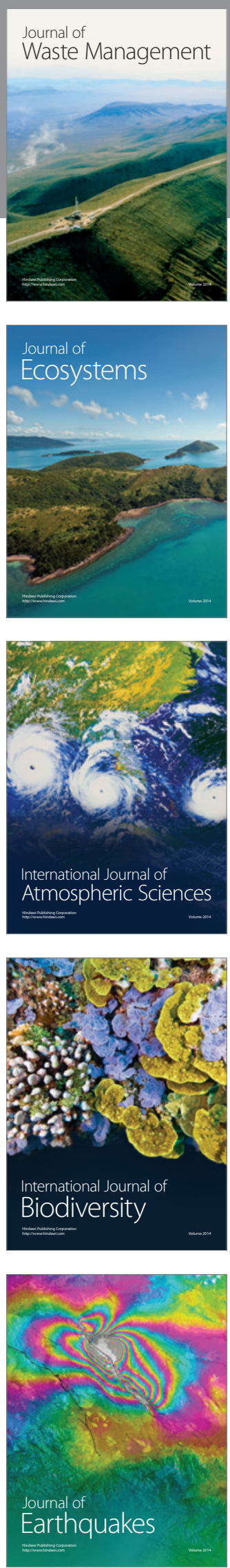
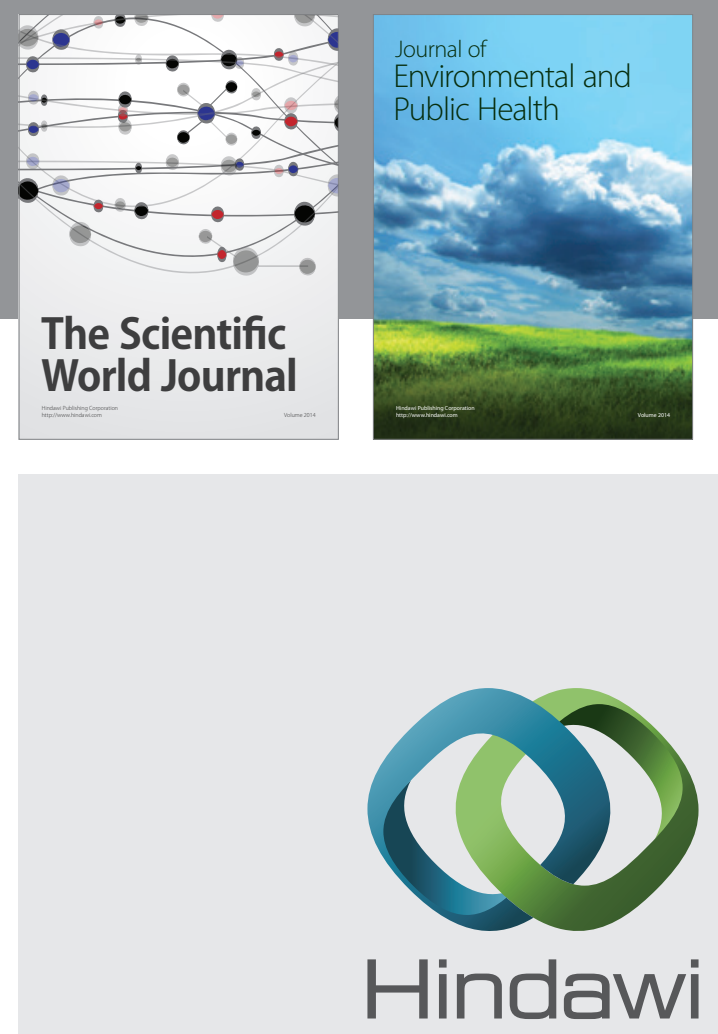

Submit your manuscripts at

http://www.hindawi.com
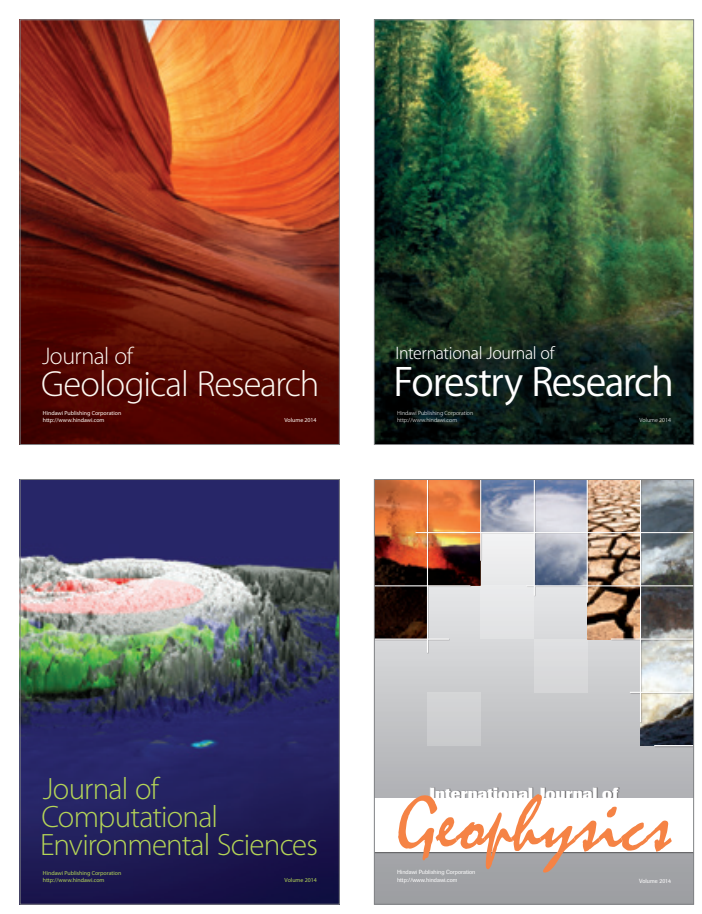
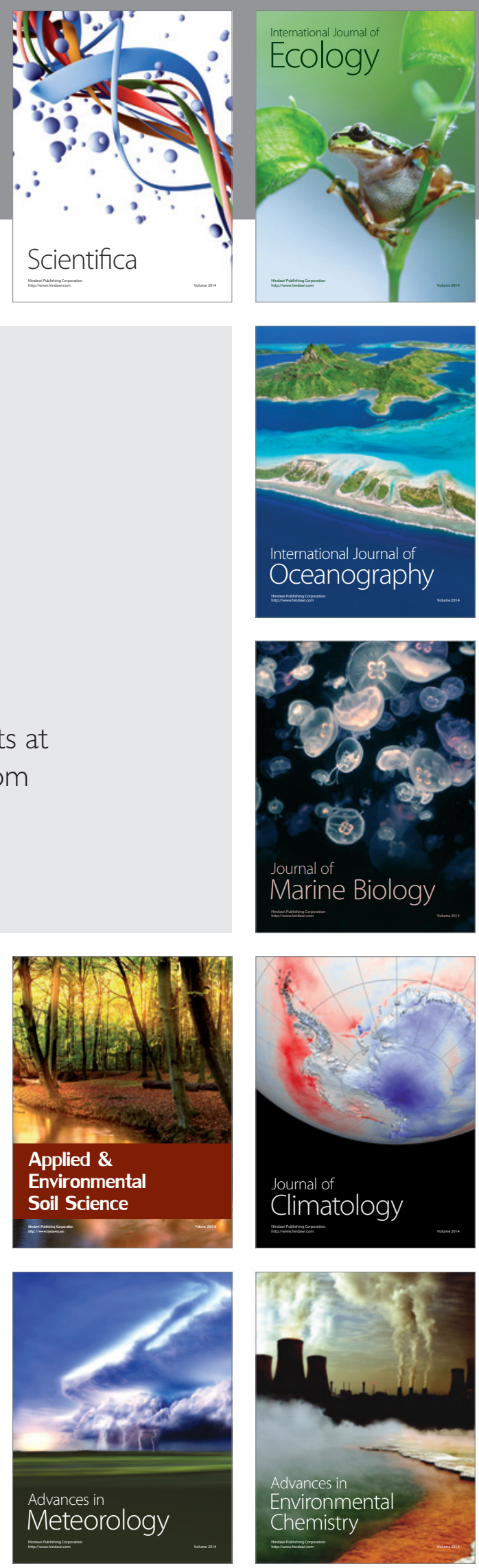